\title{
Protection of historic buildings against environmental pollution of vibrations
}

\author{
Alicja Kowalska-Koczwara ${ }^{1, a}$ and Krzysztof Stypuła² \\ ${ }^{1}$ Cracow University of Technology, Cracow, Warszawska 24 St., 31-155, Poland \\ ${ }^{2}$ Cracow University of Technology, Cracow, Warszawska 24 St., 31-155, Poland
}

\begin{abstract}
Historic buildings in Poland are largely neglected objects that small percentage is preserved in its original form. Unrelenting in the case of historic buildings is a time that brings with it the natural processes of aging of buildings, but also the history of the object which is often marked by military conflicts, fires or even incompetently carried out reconstruction. Nowadays historic buildings are also destroyed by the rapid development of infrastructure and residential construction. This development could lead to changes of water in the soil, make changes in the geologic al structure or cause exposure of the historic building to the new influences (eg. traffic vibrations), to which building has not been subjected so far. Vibrations are often omitted in environmental issues, although the protection against noise and vibration has its place in the Law on Environmental Protection. This article presents the methodology for the measurement and interpretation of vibration influence on historic buildings and the assessment methods of technical condition of historic building on the example of dynamic measurements made on St. Nicholas Church in Krakow. The importance of well-done crack-by-crack documentation and characterization of damages based on damage index is shown. Difficulties that can be encountered when determining the causes of technical condition of historic buildings are also shown. Based on the example of the Church in the article are also given the possible protection solutions of historic structures from vibrations.
\end{abstract}

\section{Introduction}

Bad condition of preservation part of the historic resources in Poland does not require a deeper explanation. The owners of historical buildings, despite of their best intentions often do not have the funds for their renovation. Time for historic buildings plays a key role. This time is closely connected with environmental influences. Environmental influences are often mistakenly identified only with air or/and water pollution. Meanwhile, air pollution [1, 2] and water [3], although it may have a significant impact on historical buildings, is not the only environmental pollution, which should be taken into account in the context of protection of historical monuments. According to art. 3 in Polish Law of Environmental Protection [4] noise and vibration are also pollution against which people and buildings should be protected. In the era of fast development of road and rail infrastructure this type of pollution can have a decisive impact on the durability of historic buildings. Unfortunately this aspect is often unnoticed or neglected.

On the effectiveness of the legal protection of historical buildings the negative influence have a lot of factors. One of them is the absence of policy adopted in the field of legal protection of historical buildings, which significantly impair the action of the administration and conservation. Another aspect of legal protection is

\footnotetext{
a Corresponding author: akowalska@pk.edu.pl
}

absence of engineering standards on protection of this specific types of buildings which are historical buildings. In this matter we can learn from our neighbours across the westernborder, who in a very transparent way describe the treatment of historic buildings in the event of vibration pollution [5]. German standard [5] apart from the whole group of buildings three categories for which vibration influences should be evaluated:

- commercial buildings, industrial buildings and building of the similar design,

- residential buildings (dwellings) and building of the similar design or occupancy,

- structures that, because of their particular sensitivity to vibration, cannot be classified as the first or second group of buildings, and are of great intrinsic value, for example listed buildings under preservation order.

Historic buildings are then considered acc. [5] in the third group of buildings, which has special conditions much stricter then first two groups. In the draft of the new Polish standard on influence of vibration on structures [6] also can be seen the regulation relating to historic buildings. This regulations says that in the case of historic buildings and buildings with valuable wall paintings, stucco, etc. through lowering the zone boundaries by assigning zone II to zone III effects. 
The scope of the performance of expertise of historic buildings is described in [7]. In article [7] seven main point of historic building expertise are described. This points are as follows:

- analysis of history of the building on the background of the history of the village and the neighbouring buildings (archival query, historic photos, archaeological research etc.),

- description of the existing state (plans, crosssections, constructional inventory, crack by crack documentation),

- "in -situ" measurements depending on the requirements (for ex. research of geotechnical conditions, research of cracks of the structure, examination of the humidity and salinity walls etc.),

- $\quad$ engineering calculations (static and / or dynamic) including verification of the existing structure,

- data analysis that will help in derivation of conclusions about the causes of damage,

- determining the scope of repair work, to remove or reduce unwanted influences,

- specify, where appropriate, specific solutions (including drawings and solutions supported by static calculations).

These seven point should be always considered in the case of historic buildings, regardless of the cause of existing damage. All these points could be found in well-done measurements made on historic buildings no matter whether it is a construction: timber-framed [8], masonry tower $[9,10]$ or masonry building [10]. In this article detailed measurements and interpretation methodology of expertise of historic building subjected to dynamic influences is presented. Two main situations will be considered: when dynamic source of excitation exists and when it doesn't. The importance of well-done crack-by-crack documentation in according to assessing of the state of cracked structure is also presented and supported by the results of expertise [11].

\section{Measurement and interpretation methodology}

In the diagnosis and design of buildings, including the influence of vibration can be divided into five cases. Diagnostic and design cases are based on the state in which the building (design, exploitation) and the source of vibration (plan, exploitation) is. In the cases of historic buildings we have got two possible situations: when the source of vibration exists and when it is in design phase, because historic building has already existed. These two cases according to [12] could be named as follows: diagnosis (vibration source exists) and diagnosis with forecast (vibration source is in design phase). These cases require a different approach to the subject. That is why they will be described in separate subsections.

\subsection{Methodology in diagnosis situation of historic building}

Diagnosis of vibration influence on historic building could be divided into following steps:

- historical analysis,

- crack-by-crack documentation with photos and cracks inventory,

- "in- situ" measurements of the dynamic influence on historic building from the existing vibration source,

- assessment of vibrational influence on historic building based on vibration results (if the historic building is subjected by standard regulation, ex. SWD scales acc. [6])

- assessment of vibrational influence on historic building based on numerical calculations (if the historic building is not subjected by standard regulation for ex. on the basis of the adopted percentage of material effort of construction).

- proposal of technical solutions to reduce vibrations in the case if the measured values (according to assessment criterion) can influence on the accelerated wear or damage to the structure of the historic building.

\subsection{Methodology in diagnosis with forecast situation of historic building}

Diagnosis with forecast differ from diagnosis in measurement situation because "in-situ" measurement cannot be done because source of vibration does not exist. "In-situ" measurements should then be replaced by so called dynamic background measurements. First of all this measurement will diagnose if existing sources of vibration influence on structure of historic building. Secondly these measurements will serve as an excitation force to validate the FEM model of the historic building.

So diagnosis with forecast will include the following steps:

- historical analysis,

- crack-by-crack documentation with photos and cracks inventory,

- dynamic background measurements,

- assessment if existing sources of vibration influence on the structure,

- creating FEM model based on results from background measurements,

- validated FEM model must then be forced by forecasted excitation taken from the similar situation,

- assessment of vibrational influence on historic building based on numerical calculations (based on standard regulation or based on the basis of the adopted assessment criterion)

- proposal of technical solutions to reduce vibrations In the case of diagnosis with forecast the FEM model is the most important. Good FEM model should 
be validated according to modal analysis and to background measurement results.

Assessment criterion should be assumed basing on whether historic building is subjected to standard regulation. For example if it is subjected to SWD scales then according to Polish standard [6] basing on vibrogram received from FEM model, analysis in 1/3 octave band could be made. If the historic building is not subjected to SWD scales then additional criterion should be adopted. It could be for example percentage of material effort derived from Huber-Mises-Hencky criterion.

\section{Consideration of cracks in the methodology for assessing the influence of vibration on historic buildings}

Historic buildings are often in bad condition and have many scratches and cracks or another damages in their structure. That is why there are some steps in above mentioned methodology which deserve special attention because they can effect on the proper performance of evaluation.

\subsection{Crack-by-crack documentation}

Examination of buildings scratches should include an inventory of scratches and cracks on internal and external elements of the object and possible observation of their stability.

During the inventory of scratches it is important to determine whether visible damage is only scratch on a plaster or is it already a crack in the structural element. Often to determine this fact it is necessary to remove the plaster, which of course in the case of historic buildings may be impossible. In [7] authors proposed classification of scratches which is as follows:

- $\quad$ scratch - visible element discontinuity of small length and usually to $0.5 \mathrm{~mm}$ width across,

- $\quad$ slot - scratch that has width across greater than 0.5 $\mathrm{mm}$,

- crack - inclined slot of a significant length (eg. through the entire length of the wall).

It is noticeable that the above mentioned classification may be useful in assessing the state of scratches, but it should be remembered that in historic buildings determining what is a scratch and what is a slot can be troublesome and often impossible. What is important is to distinguish between scratch and crack because cracks can change static scheme of the structure. Damage which is identified as a crack is usually visible inside and outside of the building wall (ex. fig. 1. and fig. 2).

Assessment of damages in historic buildings is often difficult by the lack of direct access to damage, eg. to the vault in the historic church. It is therefore important experience and curiosity of people performing an inventory of damages in such buildings. In the cases of difficulties in access to damage modern technologies can be useful, for example: digital photogrammetry, 3D

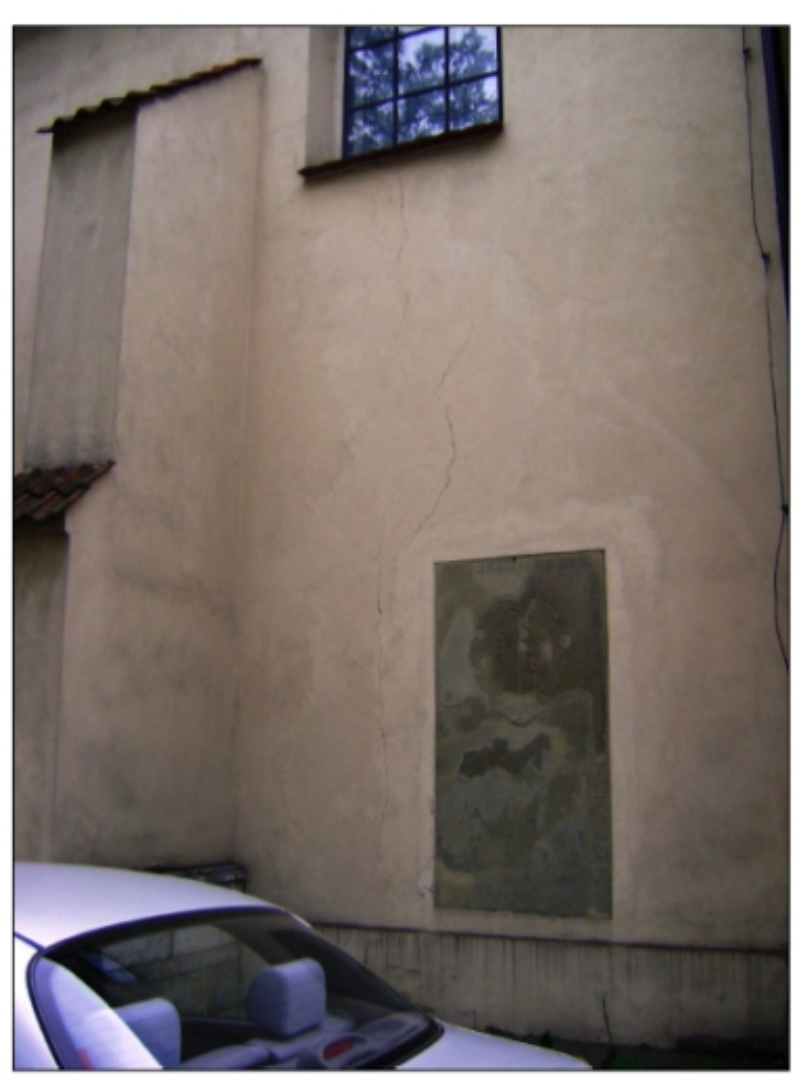

Figure 1. Crack visible on the north elevation of the St. Nicholas Church in Krakow.

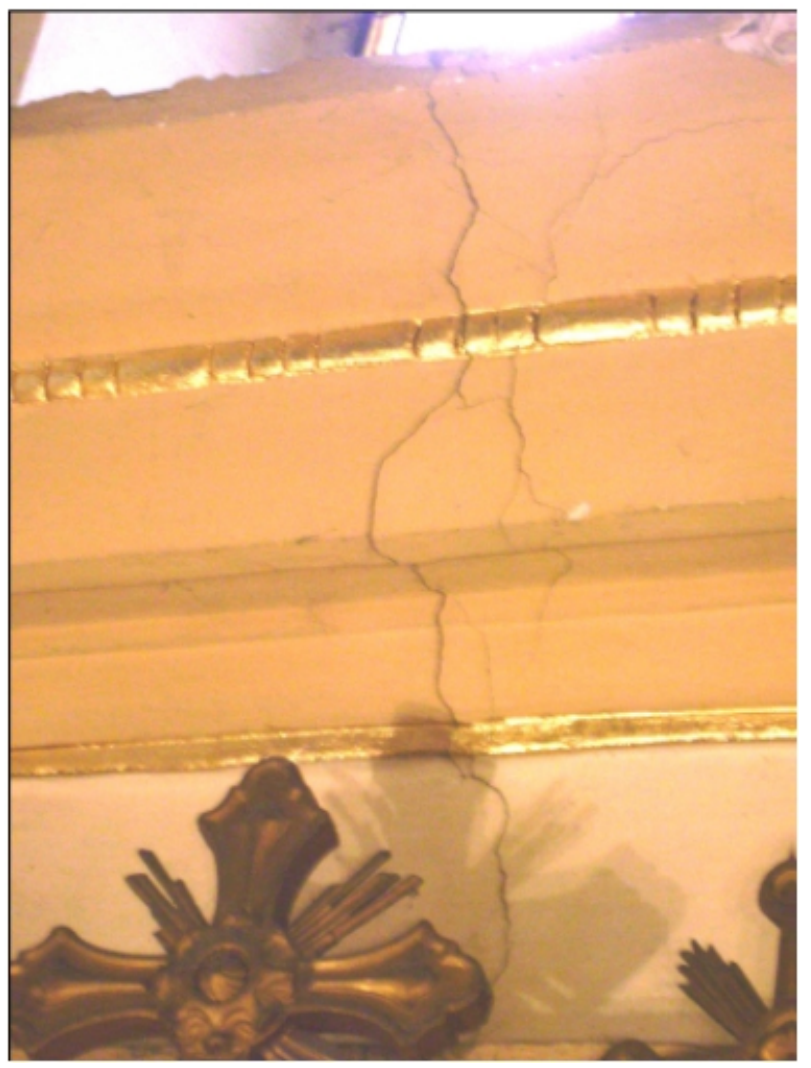

Figure 2. The crack on the wall of the north side nave of the St. Nicholas Church in Krakow. 


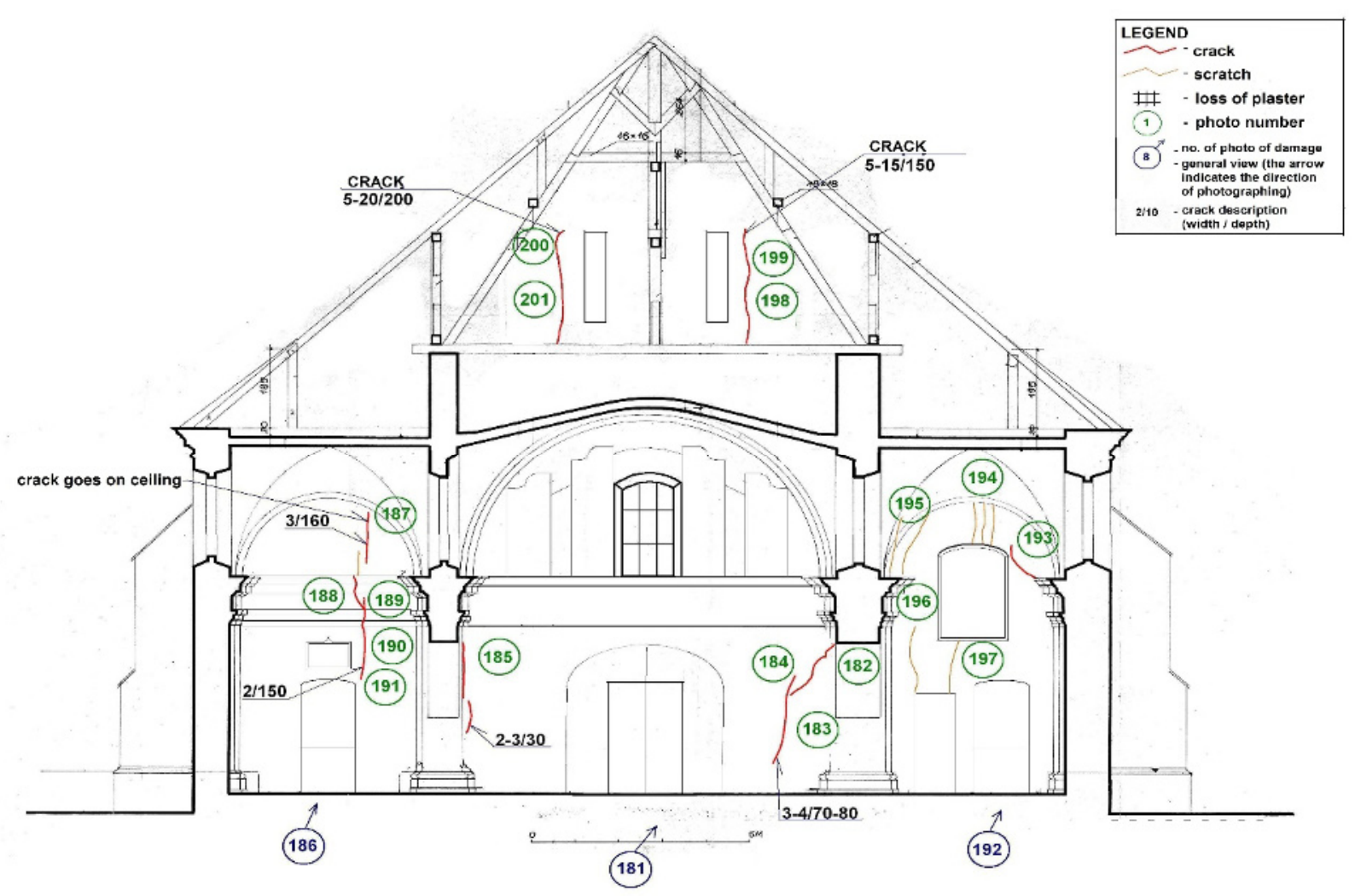

Figure 3. View of damages on the lateral walls of St. Nicholas Church in Krakow.

scanning [13] or increasingly popular thermography $[14,15]$.

For investors, but also for anyone who will be reading the results of the inventory of damage, it is important that the documentation of the inventory should be readable. That is why it is always good to performed the appropriate inventory drawings illustrating the place of occurrence

of damage, containing the type and shape and number of the photo of damage. Inventory drawings of all facades, horizontal plans and important cross-sections including all necessary information were made during performance of expertise [11] (see ex. Fig. 3). On the Fig. 3 location of damages, shape of damage, type of damage (scratch or crack), description of major damages including the width of the crack is visible. Numbers in circles including, by the contrast, the number of photography attached to the expertise with an arrow (if necessary) which describes the direction in which the photos were made.

Measurements of the stability of cracks should be done if there is a suspicion that the observed damages will have been enlarged. Then a pointer crack width could be set up to check this suspicion. Changes in width of cracks may have periodical character (due to transport excitation), could be daily repeated (due to solar radiation) or have long term character (conditioned by the change of seasons). It is therefore important to check width of cracks and observe if changes in width of cracks have periodical or permanent character.

\subsection{FEM modelling of cracks}

Inventory of damages of a building not only describes the status quo but also has an effect on the formation of computational model of a building. Nowadays, in the era of numerical calculations, there are several FEM programs allowing engineers to learn the behaviour of structures subjected to different types of loads without need for measurements on a real building. But it is important to perform a structural model accurately with regard to correctly modelled structural system, prepared on the basis of existing technical documentation or inventory of building. In the case of a damaged building, it is important to take cracks in structural elements into account.

There are mainly two approaches to this subject. The first one is to reduce stiffness in the area of crack by reduction in Young modulus [16]. Which is a good idea when the behaviour of the building as a whole is considered and when we do not need to analyse the behaviour of individual components. In this approach is good to calculate modal analysis to check accuracy of numerical model with measurements, because cracks can influence on values of natural frequencies (making them lower than for undamaged structure). It is also good to thicken the FEM mesh in the area of cracks because in stress analysis in the wicker elements is a need for more accurate calculation [17].

The second approach in FEM modelling is known as "detailed micro-modelling"[18]. In this approach cracks are modelled as a discontinuum elements. There is then a need for adjastement of contact elements, 
which always makes calculations difficult and long in time. This type of approach has an advertisement when is a need to know better the behaviur of single structural element [19].

\section{Measurement program of historic building}

The scope of well-done measurements should include some points. First of all researcher should know the aim of measurements and the way according to standards procedures to achieve this aim.

When vibration influence on building structure is considered is good to know if this building is located in the so called "zone of dynamic influences". These zones have various ranges depending on the type of vibration sources, their propagation path and the dynamic characteristics of the building. Table 1 (acc. [12]) summarizes the zones of dynamic influences of vibrations generated by different sources.

Table 1. Range of zones of dynamic influences.

\begin{tabular}{|c|c|}
\hline Source of vibration & $\begin{array}{c}\text { Range of the dynamic } \\
\text { influe nce zone }\end{array}$ \\
\hline Railway & $25-50 \mathrm{~m}$ \\
\hline Tram, road & $15-25 \mathrm{~m}$ \\
\hline Shallow underground & $40 \mathrm{~m}$ \\
\hline Driving of foundation piles & $40-60 \mathrm{~m}$ \\
\hline Soil compaction by vibratory roller & $20-60 \mathrm{~m}$ \\
\hline $\begin{array}{c}\text { Driving of sheet piling with } \\
\text { vibratory hammer }\end{array}$ & $30 \mathrm{~m}$ \\
\hline $\begin{array}{c}\text { Driving of sheet piling with shock } \\
\text { hammer }\end{array}$ & $20 \mathrm{~m}$ \\
\hline
\end{tabular}

According to Table 1 if historic building is in one of this zones then dynamic influence should be considered and could be the reason of cracks observed during inventory. So the dynamic measurements should be done and they should include following points:

- every measurement made on historic building should be done under conservatory supervision,

- local vision,

- study on historic documentation of the building, which could help to make decision on location of measurements points,

- location of measurements points in the way to take maximum information about structural behaviour under dynamic excitation and do not damage valuable elements of historic structure, dynamic signal recording,

- analysis of results according to assessment criterion (SWD scales for building which are supported to these scales, percentage of material effort in other cases).

\subsection{Analysis of historical documentation}

Study on historic documentation is always a good direction because sometimes already on this stage of expertise the cause of existing damages can be determined. During expertise [11] such recognition was also done. Fig. 4 shows acc. [20] further changes which occurred on the structure of Church of St. Nicholas .

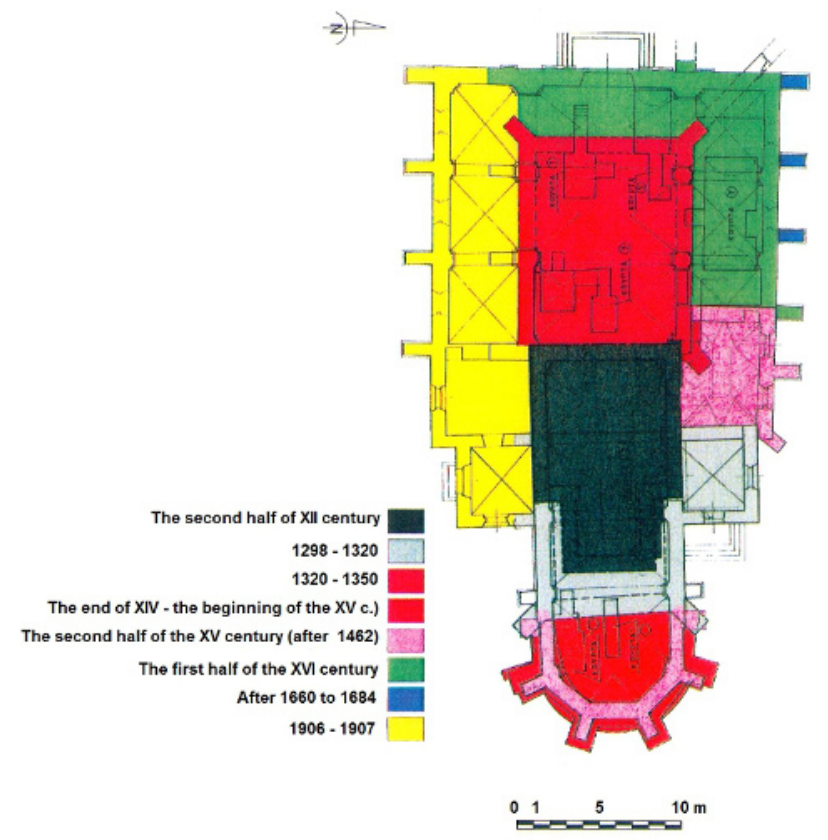

Figure 4. Development phases of the Church of St. Nicholas in Krakow (acc. [20])

On the example of this Church can be seen that historic buildings throughout history are subject to numerous reconstructions and expandability. Of course, such historical interventions can have an impact on existing damage. Historic building should therefore be evaluated in a comprehensive manner, taking into account historical conditions.

\subsection{Location of measurement points and measurements realization}

Location of measurements points should be selected so that one side does not violate the historically valuable building structure and on the other hand, to receive as much as possible information that could be used for data analysis.

To assess the influence of vibration on the building structure measurement points should always be located on the foundation of a building or on a basement wall in the ground level in a rigid node. It is good to locate another measurement points higher on the structure but in the same cross-section Location of measurement points in one plan in St. Nicholas Church is shown on Fig. 5.

Vibration recorded at the measuring points were excited by trains passages and vehicles passages along Copernicus St. St. Nicholas Church is located in Cracow near two kinematic excitation sources:

- road located $\mathrm{m}$ from the building,

- $\quad$ railway located $9 \mathrm{~m}$ from the building (distance measured from the railhead). 
They were measured vibration acceleration in three directions: $\mathrm{x}$ - horizontal direction perpendicular to excitation from passing trains, $\mathrm{y}$ - horizontal direction along the railway line and $\mathrm{z}$ - the vertical direction.

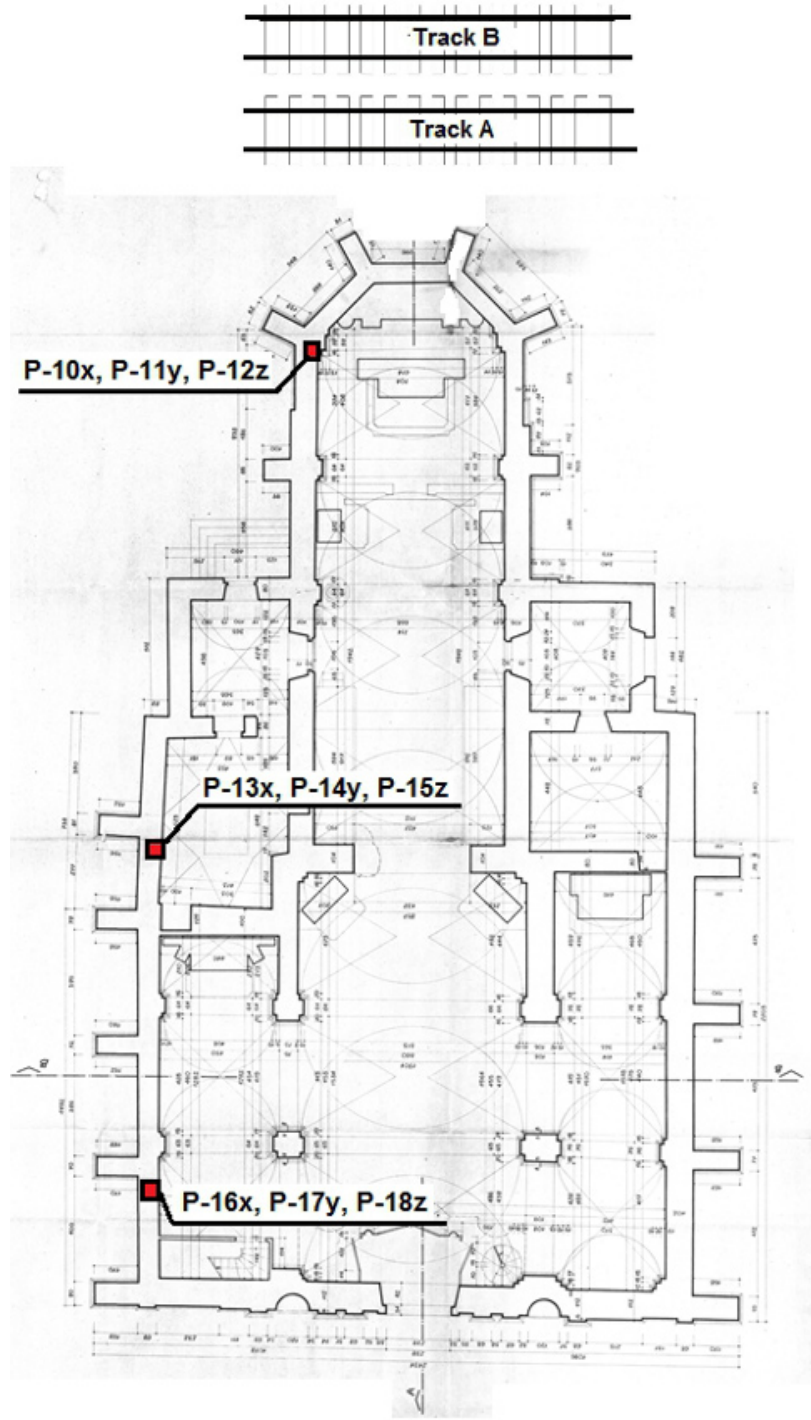

Figure 5. Location of measurement points.

The example of recorded signal in the $\mathrm{x}$ direction with one of the highest values of acceleration caused by train passage is shown on Fig. 6.

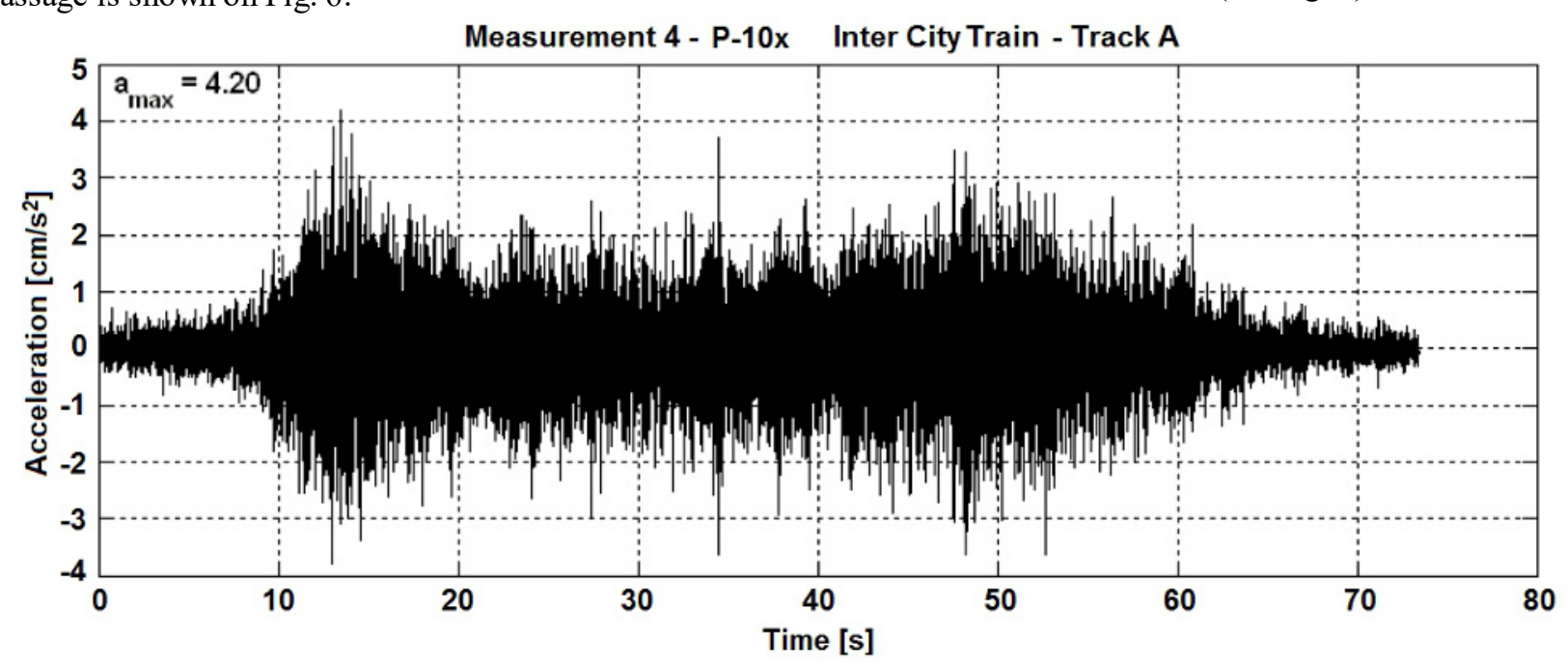

Measured vibration level of train traffic significantly exceed vibrations level recorded from passing cars on the Copernicus St.

Analysis of measurement first of all was used to validate the numerical model because the structure of St. Nicholas Church is not subjected to SWD scales. When the numerical model was validated then highest signals recorded on foundation of the Church were used as excitation in the numerical model of the structure.

\section{Mistakes in the diagnosis of historical buildings}

Historic structures are usually not very high masonry buildings that is why the most common mistake is using SWD scale as an assessment criterion to churches which are not subjected to SWD scales. SWD scales could be used for some of historic building such as presbytery or old residential houses but not for churches. Churches mostlyhas got much high open space without floors which could stiffer the structure in horizontal direction. That is why they cannot be assessed using SWD scales.

The second mistake particularly seen in relation to historic buildings is incorrect positioning of the measuring point. That is why in the case of historic building could be a problem in access to some selected points because of conservatory supervision. According to standard [6] to assess the influence of vibration on building structure recorded signal must be kinematic excitation. Signal recorded in different points then on buildings foundation or on the structural wall in rigid point on the ground level are signals that cannot be used in dynamic assessment.

Assessment of dynamic influence on building structure is based on maximum values of acceleration. However it sill happens that in the diagnosis of vibration influence on buildings RMS values are used.

There are also mistakes in measurement data analysis. The most common mistake of data analysis is the length of analysed signal. This mistake results from unclear provisions in ISO standard [21]. Fortunately in Polish standard duration of vibration is defined simple and clear.

Data analysis should cover this vibrogram section in which the values of acceleration amplitudes are greater than 0.2 of maximum value (see fig. 7 )

Figure 6. Measured acceleration signal in $\mathrm{x}$ direction on the wall on St. Nicholas Church. 


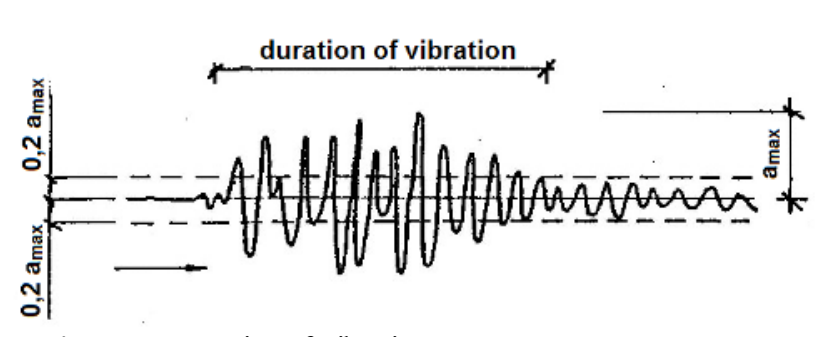

Figure 7. Duration of vibration.

There is a whole bunch of errors associated with numerical calculations. It is worth to specify these most frequent:

- mistakes in geometry of the building and in structural system,

- using triangular elements in dynamical simulations (these elements introduce numerical efforts because of their high stiffness),

- too large size of mesh elements or dismiss of cracks,

- a large number of flattened finite elements,

- wrong materials constants introduced to the model (it is difficult especially in historical structures when we do not know what kind of material was used in some elements)

- dynamic excitation not introduced in mesh node.

\section{Protection against vibrations}

Diagnosis of the building always ends with proposition of solution the existing problem. With regard to vibration pollution there are three main ways to protect the building from vibrations:

- in the source of vibrations (ex. by using vibration insulation),

- on the way of vibration propagation (ex. by partitions in the soil),

- $\quad$ in the building (ex. by using vibration insulation in the floors)

Considering historical building to introduce vibration insulation in the building could be impossible according to conservatory restrictions.

Using partitions on a way of vibration propagation could be troublesome and expensive. Another thing is good design of partition to fulfil its functions, the partition should not be too close and too far to the building. There is still a matter of location the partition and rights to land on which it would stand.

The best way to protect historical building from vibration influence is to design vibration insulation in the source. Even more the investor or owner of the transport infrastructure is forced under Polish law to eliminate the causes of pollution caused by vibration. In the final recommendations of the expertise [11] such a solution was selected.

\section{Conclusion}

The specificity of historic buildings may be associated with the lack of direct access to the visible damage or conservatory restrictions. However, this does not relieve the diagnostician to carry out reliable diagnosis of visible damage of historic structure.

Although troublesome to carry out an inventory of damage is an important element in the diagnosis of historic buildings. It provides information of existing status and is helpful in shaping the computational model of the building, with the help of which different loads scenarios can be carried out.

Well-done diagnosis should include all points mentioned in this article, and watch out for mistakes that may arise during its duration.

Each diagnosis should end with giving causing of the phenomenon and should include guidelines for the removal of the cause of damages and proposition of repairs. Especially in the case of historic buildings subjected to dynamic influences this could be the problem. That is why protection in these cases should be focused on eliminating the sources of vibration or reducing dynamic excitation coming from the source. Sometimes if necessary partitions in the soil could be considered.

\section{References}

1. F. Corvo, J. Reyes, C. Valdes, F. Villaseñor, O. Cuesta, D. Aguilar, P. Quintana. Water Air Soil Poll 205, 359-375 (2010).

2. Y. Nuhoglu, E. Oguz, H. Uslu, A. Ozbek, B. Ipekoglu, I. Ocak, I. Hasenekoglu. Sci Total Environ 364, 272 283 (2006).

3. H. Bravo, R. Soto, R. Sosa, P. Sa'nchez, A.L. Alarco'n, J. Kahl, J. Ru'z. Environ Pollut 144, 655660 (2006).

4. Act of 27 April 2001. Environmental Law (in Polish)

5. DIN 4150-3. Structural vibration. Part 3 : Effects of vibration on structures

6. prPN-B-02170P. Ocena szkodliwości drgań przekazywanych przez podłoże na budynki.

7. J. Banaszak, A. Halicka. Building and Architecture 9 51-68 (2011).

8. A. Kandemir-Yucel, A. Tavukcuoglu, E.N. CanerSaltik. Infrared Phys Techn 49, 243-248 (2007).

9. A. Carpinteri, S. Invernizzi, G. Lacidogna. Eng Struct 27, 387-395 (2005).

10. S. Ivorraa, F. J. Pallares. Eng Struct 28, 660-667 (2006).

11. K. Stypuła (head of the team of authors): Specialized constructional expertise with performing vibration measurements, dynamic computer analysis and geotechnical subsoil researches of St. Nicholas Church at St. Copernicus 9 in Krakow. Cracow University of Technology, Institute of Structural Mechanics, November 2009.

12. J. Kawecki, A. Kowalska-Koczwara, K. Stypuła. WASET 59, 1496-1502 (2011).

13. A.Rzońca. Ph.D. Thesis, Krakow 2008

14. D. Paoletti, D. Ambrosini, S. Sfarra, F. Bisegna. J Cult Herit 14, 116-121 (2013).

15. L. Binda, A. Saisi, C. Tiraboschi. Constr Build Mater 14, 199-233 (2000). 
16. I. Lubowiecka, J. Armesto, P. Arias, H. Lorenzo. Eng Struct 31, 2667-2676 (2009).

17. J. F. Unger, S. Eckardt, C. Konke. Comput. Methods Appl. Mech. Eng. 196, 4087-4100 (2007).

18. P. B. Lourenco. Prog. Struct. Engng Mater. 4, 301319 (2002).

19. T. Belytschko, R. Gracie, G. Ventura. Comput. Methods Appl. Mech. Engrg. 196, 4087-4100 (2007).

20. H. Rojkowska, W.Niewalda. Dokumentacja z badań historyczno - architektonicznych dla Kościoła św. Mikołaja przy ul. Kopernika 9 w Krakowie. Kraków $1995-97 \mathrm{r}$

21. ISO $4866: 2010$. Mechanical vibration and shockVibration of fixed structures - Guidelines for the measurement of vibrations and evaluation of their effects on structures. 